\title{
Evaluation of the Effects of Urbanization on Carbon Emissions: The Transformative Role of Government Effectiveness
}

\author{
Fuzhong Chen ${ }^{1 *}$, Aiwen Liu ${ }^{1}$, Xiuli $\mathrm{Lu}^{1 *}, \mathrm{Ru} \mathrm{Zhe}^{2 *}$, Jiachen Tong ${ }^{1}$ and Rabia Akram ${ }^{3}$ \\ ${ }^{1}$ School of International Trade and Economics, University of International Business and Economics, Beijing, China, ${ }^{2}$ School of \\ Economics, Minzu University of China, Beijing, China, ${ }^{3}$ School of Business, Guilin University of Electronic Technology, Guilin, \\ China
}

\section{OPEN ACCESS}

Edited by:

Minda Ma,

Tsinghua University, China

Reviewed by:

Muhammad Tufail,

Xi'an Jiaotong University, China

Salman Wahab,

Qingdao University, China

*Correspondence:

Fuzhong Chen

uibesitechen@126.com

Xiuli Lu

lqq2346@163.com

Ru Zhe

zheru2001@hotmail.com

Specialty section: This article was submitted to Sustainable Energy Systems and

Policies,

a section of the journal Frontiers in Energy Research

Received: 05 January 2022 Accepted: 25 January 2022 Published: 17 February 2022

\section{Citation:}

Chen F, Liu A, Lu X, Zhe R, Tong J and Akram $R$ (2022) Evaluation of the

Effects of Urbanization on Carbon Emissions: The Transformative Role of

Government Effectiveness.

Front. Energy Res. 10:848800. doi: 10.3389/fenrg.2022.848800
With the rapid economic growth and urbanization, the environment is continuously degrading, and the problem of global warming caused by increasing carbon emissions has been highly highlighted. Utilizing panel data of the Organization for Economic Cooperation and Development (OECD) countries from 1996 to 2018, this study aims to evaluate the effects of urbanization on carbon emissions and explore the transformative role of government effectiveness. To produce more accurate estimates, the approach of the feasible generalized least squares is employed, and the heteroskedastic and correlated errors are considered due to the significant differences among the OECD countries. The results suggest an inverted $U$-shaped nexus between urbanization and carbon emissions, and for most OECD countries, the enhancement of urbanization is positive to increase carbon emissions. Besides, urbanization positively contributes to government effectiveness. As a transformator, government effectiveness negatively contributes to the effects of urbanization on increasing carbon emissions. That is, with the advancement of government effectiveness, the positive role of urbanization in emitting more carbon dioxide will be transformed to help the OECD countries mitigate carbon emissions. Hence, the findings are informative for policymakers to take effective measures to accelerate the process of urbanization and formulate active measures to improve government effectiveness, thereby decreasing carbon emissions and further mitigating global warming.

Keywords: carbon emissions, urbanization, government effectiveness, transformative role, nonlinear associations, feasible generalized least squares

\section{INTRODUCTION}

In recent decades, the global climate has deteriorated, and global warming has been highly highlighted (Zhou et al., 2013). With the rapid development of economic globalization and foreign trade, remarkable achievements have been made. However, economic growth comes with a large amount of energy consumption and carbon emissions, resulting in severe environmental pollution problems. Environmental degradation is prominent with the continuous increase of carbon emissions, global warming, and other climate problems. The long-run economic growth helps improve the environmental quality and reduce environmental degradation, while population growth worsens the environmental degradation (Adem et al., 2020). As global surface temperatures increase, 
so does the likelihood of extreme weather. Warming winters coupled with cooling springs of the past decade are positively related to global warming (Shao, 2016). In addition, urbanization is closely associated with carbon emissions. Also, cities are the main body of greenhouse gas emissions and an important field for decreasing carbon emissions. Urbanization provides market demand pulling forces for economic development that accompanies energy consumption and carbon emissions. The urbanization and adjustment of industrial structure in urban development are the main driving factors of energy consumption and carbon emissions. This study, therefore, aims to examine the associations between urbanization and carbon emissions, which is greatly significant for deepening green development and realizing low-carbon transition.

With the advancement of global economic integration, urbanization has also been accelerating, affecting carbon emissions. In the recent decade, many previous studies focused on the relationships between urbanization and carbon emissions. However, the extant literature has not reached a consistent conclusion. Firstly, some prior studies claim that urbanization undoubtedly increases carbon emissions. For instance, Glaeser and Kahn (2004) argued that urbanization is vital to bring about a rapid expansion of the size of urban areas, helping reduce urban population density and increase the daily travel distance of urban residents. Thus, private cars are more likely to be frequently used, which is positive to increase carbon emissions. Besides, utilizing data from more than 80 countries over the past 2 decades, Sadorsky (2014) employed the Stochastic Impacts by Regression on Population, Affluence, and Technology (STIRPAT) model to analyze the impact of population factors on pollution. The result reveals that the higher the urbanization level, the more carbon emissions increase. Simultaneously, some previous studies also provide evidence to support that urbanization plays a pivotal role in decreasing carbon emissions. Using data from 45 major cities, Chen et al. (2008) suggested that low population density makes the use of infrastructure and public transportation inefficient, so increasing urbanization will help reduce per capita carbon emissions. By dividing more than 8,000 Austrian households into urban, semi-urban, and rural area groups, Muñoz et al. (2020) indicated that residents in urban areas have the lowest carbon footprint. Also, Zhang et al. (2020) claimed that urbanization has an economy of scale effect, which has become the main factor driving the development of non-fossil energy, which positively contributes to mitigating carbon emissions. To the best of our knowledge, only a few previous studies have explored the nonlinear associations between urbanization and emissions of carbon dioxide. For instance, utilizing data from 88 developing countries within 30 years, Martínez-Zarzoso and Maruotti (2011) suggested an inverted U-shaped relationship between urban population density and carbon emissions. Unlike most prior studies, this study not only assumes that the associations between urbanization and carbon emissions are nonlinear but also further calculates the critical values of urbanization.

A large number of previous studies have addressed the direct effects of urbanization on carbon emissions. For instance, Ali et al. (2017) suggested that urbanization enhances environmental quality by reducing carbon emissions but is not an obstacle when initiating policies employed to prevent environmental degradation. Utilizing panel data of China's 30 provinces from 2000 to 2016, Sun and Huang (2020) evaluated the carbon emission efficiency, and the results show that there is an inverted U-shaped association between urbanization and carbon emission efficiency. Nevertheless, investigating the indirect impacts of urbanization on carbon emissions, especially the indirect effects resulting from government policy intervention, helps formulate effective measures to mitigate environmental degradation. For instance, voluntary corporate climate governance efforts are essential, but not sufficient for meaningful decarbonization. Deep decarbonization will require governments to re-integrate direct carbon reduction prescriptions alongside indirect enabling climate policies (Lister, 2018). Therefore, it is necessary to strengthen government intervention in the carbon emission market. Unlike prior studies, this study further explores the transformative role of government effectiveness in the process of urbanization on carbon emissions.

Utilizing panel data of the Organization for Economic Cooperation and Development (OECD) countries from 1996 to 2018, this study aims to evaluate the impacts of urbanization on carbon emissions. The OECD is an intergovernmental international economic organization composed of 36 countries, which aims to jointly address the economic, social, and governance challenges and seize opportunities brought by globalization. As major developed and developing countries are included, this study selects the OECD countries as the sample, which is highly representative. The purpose of this study is to investigate the impacts of urbanization on carbon emissions, and the transformative role of government effectiveness is also examined. The remainder of this study is organized as follows. Literature review and hypotheses reviews related literature and puts forward research hypotheses. Methodology specifies the econometric models and statistically describes the data. Empirical analysis presents the empirical results and performs the robustness check. Further discussions verifies the indirect effects of urbanization on carbon emissions via the transformative role of government effectiveness. Conclusion and implications outline the empirical results and highlight policy recommendations.

\section{LITERATURE REVIEW AND HYPOTHESES}

\section{Previous Research on Urbanization and Carbon Emissions}

Urbanization is considered to be a process during which most of the working population changes from farmers to a non-rural population, increasing the urban population. Urbanization is becoming the most important human social change globally, especially in developing countries ( $\mathrm{Gu}, 2019)$. Urbanization is the inevitable result of social and economic development and the performance of social progress. The level of urbanization in a country or region reflects its degree of socio-economic 
development. Since a city often plays the role of an economic center, it drives the economic development of neighboring areas, and simultaneously, the improvement of the regional economic level will in turn promote the development of the city. China's urbanization has been a notable global event (Chen et al., 2016). Specially, China has witnessed a rapid improvement in its urbanization level recently (Zhang et al., 2020). Since the reform and opening up, especially with establishing the socialist market economic system, China's national economy has achieved rapid growth, and the process of urbanization began to accelerate. The rapid development of urbanization has injected new vitality into China's politics, economy, and culture, but at the same time, China's urbanization lags behind industrialization. In addition, with the acceleration of urbanization, environmental problems have also been highlighted. There is burgeoning literature dealing with the associations between urbanization and carbon emissions, which is informative and significant to the development of low-carbon cities (Xu et al., 2018). Yet the extant literature in related fields has diverged, and no unanimous conclusions have been reached. Several studies have documented that urbanization is positive to promote carbon emissions, while there are also prior studies that conclude that urbanization can reduce carbon emissions.

Firstly, previous research recognizes the critical role of urbanization in increasing carbon emissions. Prior studies usually divide urbanization into several dimensions, such as economic, land, and population urbanization, to discuss their effects on carbon emissions (Zhang and $\mathrm{Xu}, 2017$; Chen et al., 2020; Ji et al., 2020). The impacts of urbanization on carbon emissions vary with different subsystems of urbanization. For instance, Zhou et al. (2019) suggested a Kuznets curve relationship between economic urbanization and carbon emissions, and they also claimed that energy consumption related to land urbanization greatly contributes to the increase in carbon emissions. Besides, urban expansion is more significant than economic growth in promoting carbon emissions (Zhang et al., 2021). Population and gross regional domestic product (GRDP) are positively correlated with carbon emissions, and the entire built-up and urban road areas are positively correlated with carbon emissions (Pu et al., 2020; Zhang et al., 2022). Using the heterogeneous panel cointegration test, there is a long-run equilibrium cointegration relationship between urbanization and carbon emissions. Moreover, empirical results indicate that in the long term, urbanization Granger causes carbon emissions (Wang et al., 2016). A unidirectional causal relation is found running from urbanization to direct and indirect household carbon emissions, with the direct and indirect carbon emissions of households increasing 2.9 and $1.1 \%$ for every increase of $1 \%$ in urbanization (Li et al., 2015). Utilizing the approaches of the mean group (MG), pooled mean group (PMG), and dynamic fixed effect (DFE) estimation, Sheng and Guo (2016) indicated that rapid urbanization increases carbon emissions both in the short and long run.

However, the second vast strand of literature has documented the mitigating effects of urbanization on carbon emissions. The level of urbanization is negatively associated with the carbon emissions of cities. In other words, the higher the level of urbanization, the fewer carbon emissions. While energy use is one of the main driving forces of ascending carbon emissions, urbanization contributes to reducing carbon emissions (Ma et al., 2019b; Balsalobre-Lorente et al., 2021). Using panel data of China's 30 provincial-level regions from 2001 to 2014, Yao et al. (2018) employed the threshold regression and mediating effect model to investigate the impacts of the urbanization process on carbon emissions. The results show that urbanization can present an abatement effect on carbon emissions. Wang et al. (2021) claimed that urbanization decreases carbon emissions, but the impact is weak in the OECD countries since developed economies have achieved the decoupling of urbanization and carbon emissions. To be more specific, Ma et al. (2019a) argued that at the scale of urban agglomeration, some regions in China have decoupled from economic development. Also, the indirect effects of population and land urbanization on regional carbon emissions are statistically negative (Sun and Huang, 2020; Chen et al., 2022). Additionally, previous studies also investigate the impacts of urbanization on carbon emissions specific to urban industrial sectors. For instance, using panel data of China's 30 provinces from 2000 to 2015, Huo et al. (2020) examined the effects of urbanization on carbon emissions from the perspectives of the population, economy, and space, revealing that urban population and building floor space contribute negatively to carbon emissions in the urban building sector.

Moreover, there is still little literature focusing on the nonlinear impacts of urbanization on carbon emissions. Ahmed et al. (2019) analyzed the nonlinear relationship between urbanization and carbon emissions from 1971 to 2014 in Indonesia, and the results unveil an inverted U-shaped nexus between urbanization and carbon emissions. Before reaching the critical value, carbon emissions will increase with the growth of urbanization. After reaching the critical value, the increase in urbanization will reduce carbon emissions. For developing countries, urbanization means more energy consumption, which will increase carbon emissions. With the advancement of urbanization for developed countries, the awareness of environmentally friendly development will increase, and the government will be required to improve effectiveness to mitigate carbon emissions. Thus, this study proposes the following hypothesis:

Hypothesis 1 (H1). Given economic resources and other control variables, urbanization nonlinearly contributes to carbon emissions.

\section{Prior Studies on Other Factors Affecting Carbon Emissions}

A large and growing body of literature has explored the influence channels of urbanization on carbon emissions. First of all, in the process of urbanization, as the overall economic scale increases, carbon emissions will rise. But when economic growth changes from extensive to low-carbon type, the efficiency of energy use will be improved and carbon emissions tend to decrease (Sun and 
Huang, 2020). Specifically, when external shocks like the economic effects of the financial crisis, the flow trend of carbon emissions are likely to reverse (Mi et al., 2017). Furthermore, with economic development, various industrial structures have different effects on carbon emissions. The transition from agriculture to industry and services, and the co-evolution of population migration from rural to urban areas, have brought about an increase in energy consumption in three ways (Jones, 1991). The first is the mechanization of agricultural operations and the reduction in labor intensity; the second is to separate food consumers from food producers in space, making transportation demand inevitable; and the third is that modern manufacturing sectors use more energy than traditional agriculture sectors. Results from earlier studies have indicated that the tertiary industry's carbon emission efficiency is greater than that of the primary and secondary industries, and the industry, construction, and transportation are the main sectors that will increase energy consumption and carbon emissions (Ma et al., 2016). Besides, with the progress of industrialization, both technological development and management factors have played vital roles in carbon emissions (Cui and Li, 2015). If the carbon emission efficiency is decomposed into technical efficiency, industrial efficiency, and management efficiency, the management efficiency is the main cause of low carbon emissions in developed regions and industries, and the advancement of technology is the leading factor that promotes the improvement of carbon emission efficiency (Wang et al., 2019).

In the process of urbanization, the size of the population also influences carbon emissions. Through elastic models such as the STIRPAT framework, O'Neill et al. (2012) argued that population growth will have an indirect impact on carbon emissions by affecting population indicators such as population density, age structure, and family size. Specifically, prior studies have suggested that via city-level and national-level data, population density affects the level of energy consumption in transportation and electricity consumption in buildings, which in turn affects the level of carbon emissions (Lafrance and Lafrance, 1999; Marcotullio et al., 2012; Liddle, 2014; Yang et al., 2020; Li et al., 2022). In addition, utilizing micro-family-level and cross-country data, several studies have documented that energy consumption activities in transportation and housing vary with age structure and family size (Liddle, 2011; Okada, 2012).

Additionally, the scale of import, export, and cross-border investment will have a certain impact on carbon emissions. As an important driving factor of the national economy, foreign trade can reduce energy demand and emissions from energy consumption, and it is also one of the driving forces for improving carbon emission efficiency (Sbia et al., 2014; Yang et al., 2020). Besides, Chen et al. (2021a) suggested that the increased trade openness of countries along the "Belt and Road" positive contributes to carbon emissions, and the degree of impact varies with the level of carbon emissions. Moreover, trade openness has a positive indirect impact on carbon emissions through economic effects, but a negative indirect impact through energy substitution and technological effects (Chen et al., 2021a).
Also, cross-border investment increases domestic production, thereby indirectly increasing carbon emissions (Zhang, 2011).

\section{The Role of Government Effectiveness in the Effects of Urbanization on Carbon Emissions}

Government effectiveness is defined to capture perceptions of the quality of public services, the quality of the civil service and the degree of its independence from political pressures, the quality of policy formulation and implementation, and the credibility of a government's commitment to such policies (Kaufmann et al., 2011). With the rapid development of the modern economy, urbanization can also influence government effectiveness, which in turn plays a pivotal role in carbon emissions. On the one hand, urbanization promotes the soundness of the system, the advancement of technology, and the improvement of the quality of the population, which are the basis for improving government effectiveness. In particular, a government's use of technology to build smart cities can greatly improve government effectiveness. On the other hand, with the development of urbanization, the migration of population from rural to urban, economic and social construction, and the emergence of innovations will put forward higher requirements on the governance level of the economic system, social mechanisms, relevant laws, regulations, and urban construction, which requires a government to improve its effectiveness. In addition, in the process of urbanization, individuals have gradually met their basic living needs and improved their living standards, and then pursue a higher level of welfare satisfaction, which also requires an improvement in the level of government services. There are few studies on the associations between urbanization and government effectiveness. This study assumes that with the promotion of urbanization, government effectiveness will continuously improve, such as the level of formulating laws and regulations, the supervision of the market, the level of law enforcement, the implementation of policies, and government services. Therefore, the hypothesis is put forward as follows:

Hypothesis $2(\mathrm{H} 2)$. Urbanization is positively associated with government effectiveness; that is, as the level of urbanization rises, government effectiveness will be further improved.

Government effectiveness is considered an important factor in achieving sustainability of environmental policies, rational uses of natural resources, and environmental protections. Prior research has exhibited that with the increase in economic welfare in the process of urbanization, government governance and imports help mitigate carbon emissions (Ronaghi et al., 2020). While imports may only transfer emissions from importing countries to exporting countries, improving government effectiveness is a key factor in decreasing pollution emissions. Therefore, a government has played a vital role in affecting the effects of urbanization on carbon emissions. Government effectiveness is considered to affect all areas of a country, such as economic development, the rule of law, regulatory quality, environmental protection, energy use, and the like (Gholipour and Farzanegan, 2018; Chen et al., 2021b). By improving government effectiveness, such as 
adopting appropriate and sustainable policies, formulating compliance measures, implementing reasonable laws, and increasing illegal costs, governments tend to effectively adopt environmental protection and sustainable policies (Jayachandran, 2015). Hence, government effectiveness may, directly and indirectly, affect carbon emissions. Government effectiveness is a pivotal moderator in seeking a balance between urbanization development and carbon emissions.

Firstly, the effectiveness of government regulation affects carbon emissions and thereby plays a crucial role in environmental quality (Esty and Porter, 2005). Reasonable government regulation is the foundation of the market economy, and it plays a vital role in promoting the effective operation of the market ( $\mathrm{Wu}, 2007)$. The effectiveness of governance, such as issuing government permits and licenses, taxation policies, market systems, laws, and regulations, helps control carbon emissions. To be more specific, prior studies have revealed that there are significant differences in the number of control measures that affect the level of carbon emissions in various countries, and all governance is affected by national decisions (Halkos and Tzeremes, 2013). Simultaneously, governments can formulate a reasonable index system on carbon emissions to guide the market economic activities. If there are clear rules, control measures for carbon emissions will be implemented more easily, which will benefit companies that comply with carbon emission regulations. Yet if there are loopholes in the rules, it may benefit companies that violate carbon emission regulations. Improving government effectiveness helps eliminate market failures, and proper governance specific to market activities is positive to promote the enhancement of carbon emission efficiency (Jalilian et al., 2007).

Secondly, in the process of urbanization, a government's effective guidance to enterprises and individuals is also pivotal to alleviate carbon emissions. Governments with higher effectiveness usually pay more attention to environmentally friendly development, guiding enterprises to strengthen technological innovation in environmental protection, using more clean energy, and adopting technologies that minimize environmental damage for industrial production (Jingchao and Kotani, 2012; Sereenonchai et al., 2017). Moreover, it can also use various measures to encourage individuals in cities to adopt a low-carbon and environmentally-friendly lifestyle, such as using more public transportation (Haustein and Hunecke, 2007; Ciotlaus et al., 2017).

Thirdly, government fiscal expenditures also have an impact on carbon emissions. Previous studies have documented that industrialization, international trade, and technical levels are positive to improve carbon efficiency, while fiscal expenditure and energy consumption affect how close efficiency is to the optimal level (Zeng et al., 2019). Government intervention has a positive impact on changes in carbon emission efficiency. Taking China as an example, Sun and Huang (2020) showed that governments guide the formulation and implementation of emission reduction plans, and fiscal expenditures in environmental upgrading have greatly encouraged the development and application of cleaner production technologies. The results also suggest that the intervention of China's

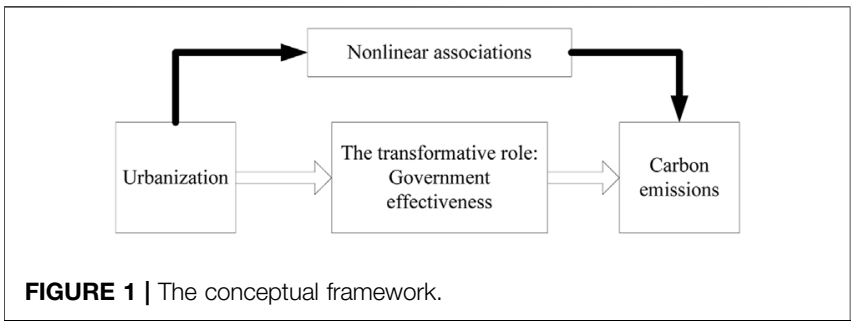

government is effective and powerful, and government fiscal expenditure on environmental protection is the main impetus for the construction of a green economy.

Additionally, in addition to formulating and implementing policies, countries with higher government effectiveness can allocate more resources to promote society to reduce carbon emissions. A more effective government will have lower bureaucracy, more efficient public services, greater financial integrity, and stronger allocation capabilities of public resources (Heinrich, 1999; De Koker and Jentzsch, 2013). It also can gain the confidence of corporate producers and enforce laws and regulations related to carbon dioxide emissions with greater efforts (Gani, 2012). Moreover, government effectiveness can also affect participation in environmental protection. Previous research has claimed that there is a positive relationship between public participation in decision-making and judicial justice in environmental affairs (Gera, 2016). Meanwhile, governments can also create better conditions for non-governmental organizations concerning environmental protection ( $\mathrm{Li}$ et al., 2018). If national governance lacks coherence, it weakens the negotiation and interaction between civil society groups.

In light of the aforementioned discussions, the enhancement of government effectiveness negatively contributes to the effects of urbanization on carbon emissions. Therefore, government effectiveness plays a transformative role and positively changes the original pattern of urbanization affecting carbon emissions. Thus, this study hypothesizes as follows:

Hypothesis 3 (H3). The impacts of urbanization on carbon emissions are transformed by government effectiveness; that is, with the advancement of government effectiveness, the positive role of urbanization in emitting more carbon dioxide will transform to decrease carbon emissions.

\section{METHODOLOGY}

\section{The Conceptual Framework}

Based on the aforementioned discussions in prior studies, the associations between urbanization and carbon emissions are assumed to be nonlinear. Therefore, there is a critical value specific to urbanization, below and above of which changes the impact of urbanization on carbon emissions. Furthermore, urbanization also has an indirect impact on carbon emissions through government effectiveness. On the one hand, with the advancement of urbanization, government effectiveness has been substantially enhanced. On the other hand, more effective governments help mitigate carbon emissions during the 


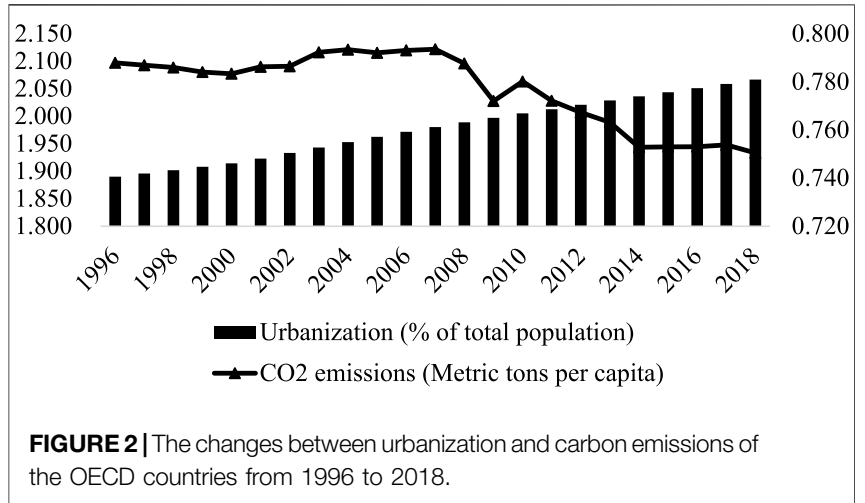

process of urbanization. Government effectiveness is considered to be a transformator in the channel of urbanization affecting carbon emissions. The conceptual framework of this study is displayed in Figure 1.

\section{Econometric Specifications}

The purpose of this study is to evaluate the effects of urbanization on carbon emissions. Following the approach of Chen and Jiang (2021), this study specifies the baseline model as follows:

$$
\text { lncarbem }_{i t}=\alpha_{0}+\beta_{1} \text { rurbpop }_{i t}+\sum_{k=1}^{N} \gamma_{k} X_{k, i t}+\mu_{i}+\omega_{t}+\varepsilon_{i t}
$$

In Eq. 1, $i$ and $t$ denote the country and year, respectively. lncarbem stands for the dependent variable of carbon emissions. The independent variable of urbanization is represented by rurbpop, which is measured by the proportion of the urban population in total population. Meanwhile, $\alpha, \beta$, and $\gamma$ are the coefficients of the constant term, urbanization (rurbpop), and control variables, respectively. $N$ is the number of the control variables, and $\varepsilon_{i t}$ is the disturbance term. Besides, all country dummies $\left(\mu_{i}\right)$ and year dummies $\left(\omega_{t}\right)$ are included to produce more accurate estimates. Following the specification of Ali et al. (2021) and Huang et al. (2022), the variables such as the exports of goods and services (lnexport), real GDP $(\ln r g d p)$, imports of goods and services (lnimport), gross savings (lngrosav), hightechnology exports (lnhtexpt), the labor force (lnlabfor), and arable land (arland) are incorporated as control variables. Except for the variables of rurbpop and arland, this study takes all other variables in the natural logarithm forms.

To capture the nonlinear effects of urbanization on carbon emissions, this study also includes the squared term of urbanization (rurbpop2) into the econometric estimates, which is specified as follows:

$$
\begin{aligned}
\operatorname{lncarbem}_{i t}= & \alpha_{0}+\beta_{1} \text { rurbpop }_{i t}+\beta_{2} \operatorname{rurbpop}_{i t}+\sum_{k=1}^{N} \gamma_{k} X_{k, i t} \\
& +\mu_{i}+\omega_{t}+\varepsilon_{i t}
\end{aligned}
$$

In addition to an evaluation of the nonlinear effects of urbanization on carbon emissions, this study also addresses the transformative role of government effectiveness $(g e)$. In this study, the variable of government effectiveness works as a

\begin{tabular}{|c|c|c|c|c|c|}
\hline Variables & & Mean & Std. Dev & Min & Max \\
\hline \multirow[t]{3}{*}{ Incarbem } & Overall & 11.467 & 1.593 & 7.528 & 15.569 \\
\hline & Between & & 1.610 & 7.671 & 15.497 \\
\hline & Within & & 0.116 & 11.102 & 11.909 \\
\hline \multirow[t]{3}{*}{ rurbpop } & Overall & 0.761 & 0.112 & 0.506 & 0.980 \\
\hline & Between & & 0.112 & 0.522 & 0.975 \\
\hline & Within & & 0.020 & 0.661 & 0.839 \\
\hline \multirow[t]{3}{*}{ rurbpop2 } & Overall & 0.591 & 0.167 & 0.257 & 0.960 \\
\hline & Between & & 0.166 & 0.272 & 0.950 \\
\hline & Within & & 0.031 & 0.431 & 0.725 \\
\hline \multirow[t]{3}{*}{ Inexport } & Overall & 25.528 & 1.458 & 21.575 & 28.563 \\
\hline & Between & & 1.382 & 22.436 & 28.044 \\
\hline & Within & & 0.517 & 24.156 & 26.558 \\
\hline \multirow[t]{3}{*}{ Inrgdp } & Overall & 22.004 & 1.602 & 18.565 & 25.999 \\
\hline & Between & & 1.599 & 19.105 & 25.770 \\
\hline & Within & & 0.280 & 21.144 & 24.225 \\
\hline \multirow[t]{3}{*}{ Inimport } & Overall & 25.513 & 1.434 & 21.687 & 28.769 \\
\hline & Between & & 1.364 & 22.449 & 28.305 \\
\hline & Within & & 0.496 & 24.201 & 26.422 \\
\hline \multirow[t]{3}{*}{ Ingrosav } & Overall & 24.956 & 1.721 & 19.456 & 29.030 \\
\hline & Between & & 1.690 & 21.282 & 28.539 \\
\hline & Within & & 0.426 & 23.131 & 26.110 \\
\hline \multirow[t]{3}{*}{ Inhtexpt } & Overall & 23.068 & 1.810 & 18.369 & 26.232 \\
\hline & Between & & 1.824 & 19.087 & 25.994 \\
\hline & Within & & 0.191 & 21.833 & 24.449 \\
\hline \multirow[t]{3}{*}{ Inlabfor } & Overall & 15.608 & 1.504 & 11.943 & 18.925 \\
\hline & Between & & 1.522 & 12.111 & 18.848 \\
\hline & Within & & 0.083 & 15.333 & 15.915 \\
\hline \multirow[t]{3}{*}{ arland } & Overall & 0.298 & 0.280 & 0.027 & 1.419 \\
\hline & Between & & 0.279 & 0.033 & 1.232 \\
\hline & Within & & 0.051 & 0.065 & 0.530 \\
\hline \multirow[t]{3}{*}{ ge } & Overall & 1.303 & 0.575 & -0.265 & 2.354 \\
\hline & Between & & 0.556 & 0.123 & 2.080 \\
\hline & Within & & 0.171 & 0.717 & 1.872 \\
\hline
\end{tabular}
transformator which is moderated with the variable of
TABLE 1 | Statistical description of panel data.

Notes: The number of observations is 828 . In addition, the $N$ and $T$ of the panel data are 36 and 23, respectively.

urbanization and thereby together affect carbon emissions. The interactive terms of ge specific to rurbpop and rurbpop 2 are included and are represented by $t s f m 1$ (rurbpop $\left.{ }_{i t} \times g e_{i t}\right)$ and $t s f m 2$ (rurbpop $2_{i t} \times g e_{i t}$ ), respectively. Therefore, this study specifies the transformative role regressions as follows:

$g e_{i t}=\alpha_{0}+\rho_{1}$ rurbpop $_{i t}+\rho_{2} \operatorname{rurbpop}_{i t}+\sum_{k=1}^{N} \gamma_{k} X_{k, i t}+\mu_{i}+\omega_{t}+\varepsilon_{i t}$

lncarbem $_{i t}=\alpha_{0}+\varphi_{1} t s f m 1+\varphi_{2} t s f m 2+\sum_{k=1}^{N} \gamma_{k} X_{k, i t}+\mu_{i}+\omega_{t}+\varepsilon_{i t}$

In Eq. 3, $\rho_{1}$ and $\rho_{2}$ are the coefficients of the variables urbanization (rurbpop) and its squared term (rurbpop2), respectively. In this study, the associations between urbanization and carbon emissions are assumed to be nonlinear as well. In Eq. 4, $\varphi_{1}$ and $\varphi_{2}$ denote the coefficients of the interactive terms of tsfm 1 and $t s f m 2$.

\section{Data Source and Description}

The panel data utilized in this study comes from the World Development Indicators (WDI) and Worldwide Governance Indicators (WGI), and these two datasets are supported and provided by the World Bank. In detail, the data of government 
TABLE 2 | Results of baseline estimations.

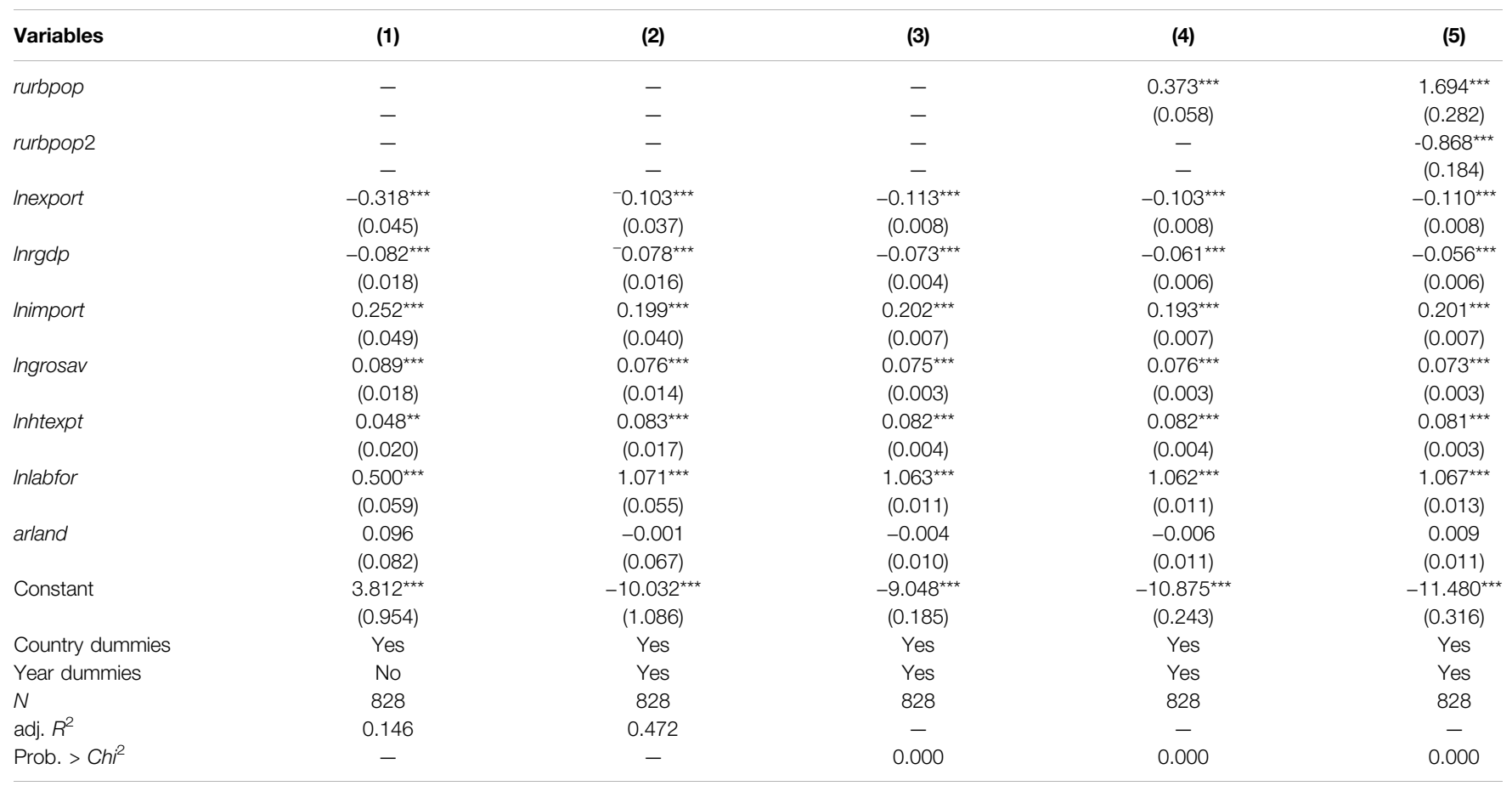

Notes: In Columns (1) and (2), the data in parentheses are standard errors, and these in Columns (3) to (5) are heteroskedastic and correlated errors. Moreover, ${ }^{*}$ ** and ${ }^{* * *}$ denote $10 \%, 5 \%$ and $1 \%$ significance level, respectively.

effectiveness are from WGI, and that of other variables are from WDI. This study selects the OECD countries as the research samples. Since the main developed and developing countries are incorporated, the samples are of high representativeness. Figure 2 displays the changing trends of urbanization and carbon emissions in the OECD countries since 1996. According to Figure 2, with the development of the economy and society, the average urbanization level of the OECD countries is continuously increasing. Carbon emissions increased slowly but began to decrease after 2007, indicating an inverted U-shape. Thus, the rough change trends of urbanization and carbon emissions are consistent with $\mathrm{H} 1$; that is, the associations between them are nonlinear.

In this study, all 36 OECD member countries are included as samples. Due to the data availability, the research data is from 1996 to 2018, since most variables before 1996 and in 2019 and 2020 have a large number of missing values. As for the variable of regulatory quality, the data in 1997, 1999, and 2001 are missing. Following the method of Huang et al. (2022), this study imputed the missing values in 1997, 1999, and 2001 using the mean of the data in 1996 and 1998, the mean of the data in 1998 and 2000, and the mean of the data in 2000 and 2002, respectively. Additionally, other missing values of related variables are filled in with the mean values of the data of two consecutive years. Therefore, the sample size is 828 , and the panel data used in this study are balanced with 36 countries $(\mathrm{N})$ and 23 years $(\mathrm{T})$.

Table 1 reports the results of descriptive statistics. For the dependent variable of carbon emissions, the mean, minimum and maximum values are 11.467, 7.528, and 15.569, respectively. Meanwhile, the standard deviations of carbon emissions specific to overall and between the OECD countries are 1.593 and 1.610, which reveals that the differences of carbon emissions between the OECD countries are even larger than that of all the sampling countries. With regard to the independent variable of urbanization, the mean value is 0.761 , as well as the minimum and maximum values are 0.506 and 0.980 , respectively. Additionally, the standard deviation is 0.112 , which means that the differences in urbanization among the OECD countries are insignificant. However, to produce more accurate estimates, the heteroscedasticity of the dependent variable needs to be considered.

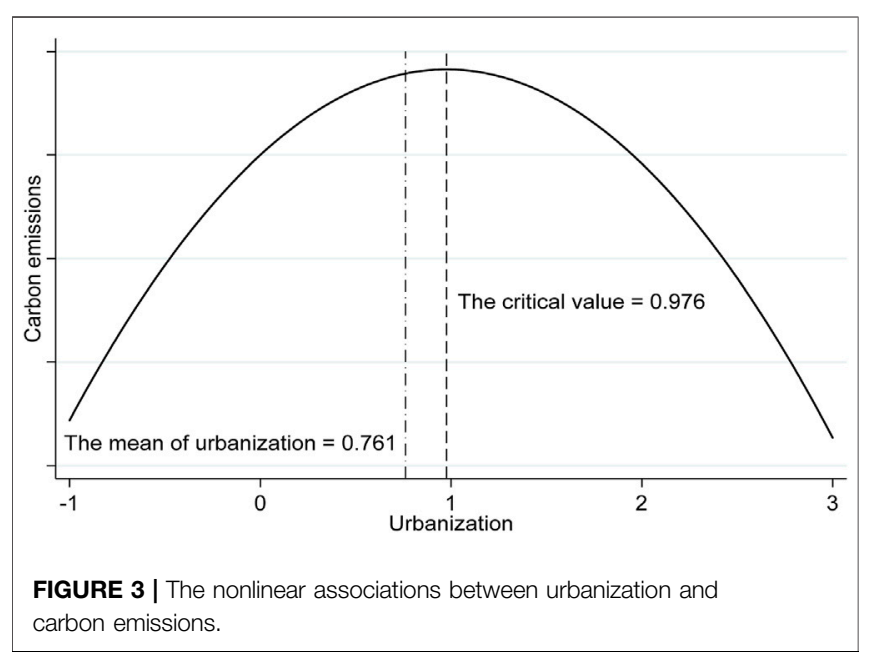


TABLE 3 | Results of robustness check.

\begin{tabular}{|c|c|c|c|c|}
\hline Variables & (1) & (2) & (3) & (4) \\
\hline rurbpop & $\begin{array}{l}2.577^{\star \star} \\
(1.306)\end{array}$ & $\begin{array}{c}-11.962^{\star \star \star} \\
(2.351)\end{array}$ & $\begin{array}{l}3.669^{\star} \\
(2.021)\end{array}$ & $\begin{array}{l}1.949^{\star \star \star} \\
(0.223)\end{array}$ \\
\hline rurbpop2 & $\begin{array}{c}-1.553^{\star} \\
(0.856)\end{array}$ & $\begin{array}{c}8.025^{\star \star \star} \\
(1.430)\end{array}$ & $\begin{array}{c}-2.953^{\star} \\
(1.606)\end{array}$ & $\begin{array}{c}-1.083^{\star \star \star} \\
(0.142)\end{array}$ \\
\hline Inexport & $\begin{array}{l}-0.006 \\
(0.035)\end{array}$ & $\begin{array}{c}-0.108^{\star \star} \\
(0.053)\end{array}$ & $\begin{array}{c}-0.215^{\star \star \star} \\
(0.066)\end{array}$ & $\begin{array}{c}-0.077^{\star \star \star} \\
(0.009)\end{array}$ \\
\hline Inrgdp & $\begin{array}{l}-0.023 \\
(0.018)\end{array}$ & $\begin{array}{l}0.066^{\star} \\
(0.040)\end{array}$ & $\begin{array}{c}-0.067^{\star \star \star} \\
(0.020)\end{array}$ & $\begin{array}{c}-0.040^{\star \star \star} \\
(0.005)\end{array}$ \\
\hline Inimport & $\begin{array}{l}-0.001 \\
(0.035)\end{array}$ & $\begin{array}{c}0.061 \\
(0.052)\end{array}$ & $\begin{array}{c}0.268^{\star \star \star} \\
(0.067)\end{array}$ & $\begin{array}{c}0.187^{\star \star \star} \\
(0.009)\end{array}$ \\
\hline Ingrosav & $\begin{array}{l}0.091^{\star \star \star} \\
(0.008)\end{array}$ & $\begin{array}{l}0.064^{\star \star \star} \\
(0.018)\end{array}$ & $\begin{array}{l}0.064^{\star \star} \\
(0.027)\end{array}$ & $\begin{array}{c}0.083^{\star \star \star} \\
(0.003)\end{array}$ \\
\hline Inhtexpt & $\begin{array}{c}0.100^{\star \star \star} \\
(0.013)\end{array}$ & $\begin{array}{c}0.055^{\star \star \star} \\
(0.021)\end{array}$ & $\begin{array}{c}0.087^{\star \star \star} \\
(0.033)\end{array}$ & $\begin{array}{c}0.085^{\star \star \star} \\
(0.004)\end{array}$ \\
\hline Inlabfor & $\begin{array}{c}0.865^{\star \star \star} \\
(0.053)\end{array}$ & $\begin{array}{c}0.716^{\star \star \star} \\
(0.125)\end{array}$ & $\begin{array}{c}1.299^{\star \star \star} \\
(0.095)\end{array}$ & $\begin{array}{c}0.385^{\star \star \star} \\
(0.015)\end{array}$ \\
\hline arland & $\begin{array}{l}0.180^{\star \star \star} \\
(0.067)\end{array}$ & $\begin{array}{c}-0.307^{\star \star \star} \\
(0.092)\end{array}$ & $\begin{array}{c}0.121 \\
(0.115)\end{array}$ & $\begin{array}{c}0.099^{\star * *} \\
(0.011)\end{array}$ \\
\hline Constant & $\begin{array}{c}-7.253^{\star \star \star} \\
(1.242)\end{array}$ & $\begin{array}{c}3.115 \\
(2.469)\end{array}$ & $\begin{array}{c}-12.048^{\star \star \star} \\
(1.980)\end{array}$ & $\begin{array}{c}-10.606^{\star \star \star x} \\
(0.327)\end{array}$ \\
\hline Country dummies & Yes & Yes & Yes & Yes \\
\hline Year dummies & Yes & Yes & Yes & Yes \\
\hline$N$ & 828 & 467 & 361 & 828 \\
\hline adj. $R^{2}$ & 0.998 & 0.998 & 0.997 & - \\
\hline Prob. $>C h i^{2}$ & - & - & - & 0.000 \\
\hline
\end{tabular}

As for the control variables, the average exports and imports of goods and services are 25.528 and 25.513, respectively. Due to high standard deviations of 1.458 and 1.434, there are also large differences in import and export trade among the OECD member countries. Concerning the deflated GDP, the mean value is 22.004 with minimum and maximum values of 18.565 and 25.999 , indicating the huge gap in economic size among the OECD countries. Besides, the mean values of the gross savings, high-technology exports, and labor force are 24.956, 23.068, and 15.608 with standard deviations of $1.721,1.824$, and 1.504, respectively. Also, the mean value of arable land is 0.298 with a standard deviation of 0.280 . For the transformator variable, the average government effectiveness is 1.303 , and the standard deviation is as high as 0.575 . Hence, regardless of the control variables and transformator variable of the OECD countries, the results of statistical description suggest significant differences among the sampling countries, which indicates that the heteroscedasticity needs to be taken into account as well.

\section{EMPIRICAL ANALYSIS}

\section{Results of Baseline Estimations}

Utilizing the panel data from 1996 to 2018 for the OECD countries, this study seeks to evaluate the effects of urbanization on carbon emissions as well as the transformative role of government effectiveness. Firstly, this study verifies whether to use the regressions of the pooled ordinary least squares (POLS), random-effect (RE), or fixed-effect (FE). As for the POLS and $\mathrm{FE}$ regressions, this study utilizes the $\mathrm{F}$ test specific to all the
TABLE 4 | Results of the transformative role of government effectiveness.

\begin{tabular}{|c|c|c|c|}
\hline Variables & (1) & (2) & (3) \\
\hline rurbpop & $\begin{array}{l}1.694^{\star \star \star} \\
(0.282)\end{array}$ & $\begin{array}{c}-1.717^{\star \star \star} \\
(0.527)\end{array}$ & $\begin{array}{l}- \\
-\end{array}$ \\
\hline rurbpop2 & $\begin{array}{c}-0.868^{\star \star \star} \\
(0.184)\end{array}$ & $\begin{array}{l}1.323^{\star \star \star} \\
(0.343)\end{array}$ & - \\
\hline tsfm 1 & - & - & $\begin{array}{c}0.570^{\star \star \star} \\
(0.018)\end{array}$ \\
\hline tsfm2 & - & - & $\begin{array}{c}-0.387^{\star \star \star} \\
(0.021)\end{array}$ \\
\hline Inexport & $\begin{array}{c}-0.110^{\star \star \star} \\
(0.008)\end{array}$ & $\begin{array}{c}-0.102^{\star \star \star} \\
(0.017)\end{array}$ & $\begin{array}{c}-0.084^{\star \star \star} \\
(0.007)\end{array}$ \\
\hline $\ln r g d p$ & $\begin{array}{c}-0.056^{\star \star \star} \\
(0.006)\end{array}$ & $\begin{array}{c}0.032^{\star \star \star} \\
(0.007)\end{array}$ & $\begin{array}{c}-0.079^{\star \star \star} \\
(0.004)\end{array}$ \\
\hline Inimport & $\begin{array}{c}0.201^{\star \star \star} \\
(0.007)\end{array}$ & $\begin{array}{c}0.289^{\star \star \star} \\
(0.017)\end{array}$ & $\begin{array}{c}0.138^{\star \star \star} \\
(0.007)\end{array}$ \\
\hline Ingrosav & $\begin{array}{c}0.073^{\star \star \star} \\
(0.003)\end{array}$ & $\begin{array}{c}0.057^{\star \star \star} \\
(0.005)\end{array}$ & $\begin{array}{c}0.063^{\star \star \star} \\
(0.003)\end{array}$ \\
\hline Inhtexpt & $\begin{array}{c}0.081^{\star \star \star} \\
(0.003)\end{array}$ & $\begin{array}{c}0.070^{\star \star \star} \\
(0.007)\end{array}$ & $\begin{array}{c}0.072^{\star \star \star} \\
(0.004)\end{array}$ \\
\hline Inlabfor & $\begin{array}{l}1.067^{\star \star \star} \\
(0.013)\end{array}$ & $\begin{array}{c}-0.686^{\star \star \star} \\
(0.029)\end{array}$ & $\begin{array}{l}1.230^{\star \star \star} \\
(0.011)\end{array}$ \\
\hline arland & $\begin{array}{c}0.009 \\
(0.011)\end{array}$ & $\begin{array}{c}0.001 \\
(0.037)\end{array}$ & $\begin{array}{c}0.012 \\
(0.015)\end{array}$ \\
\hline Constant & $\begin{array}{c}-11.480^{\star \star \star} \\
(0.316)\end{array}$ & $\begin{array}{c}4.869^{\star \star \star} \\
(0.520)\end{array}$ & $\begin{array}{c}-11.413^{\star \star \star} \\
(0.145)\end{array}$ \\
\hline Country dummies & Yes & Yes & Yes \\
\hline Year dummies & Yes & Yes & Yes \\
\hline$N$ & 828 & 828 & 828 \\
\hline Prob. $>\mathrm{Chi}^{2}$ & 0.000 & 0.000 & 0.000 \\
\hline
\end{tabular}

Notes: The data in parentheses are heteroskedastic and correlated errors. Moreover, ${ }^{*}$ ** and ${ }^{* * *}$ denote $10 \%, 5 \%$ and $1 \%$ significance level, respectively.

intercept terms, and the results show that $\mathrm{F}(35,784)=255.940$, rejecting the null hypothesis of the POLS regression at a significance of $1 \%$. Furthermore, with regard to the $\mathrm{FE}$ and $\mathrm{RE}$ regressions, this study employs the Hausman test. The results suggest that $\mathrm{Chi}^{2}(8)=76.220$, which means that the null hypothesis of the RE regression is rejected. Thus, compared with the POLS and RE regressions, the approach of the FE regression is more adequate in this study. Secondly, for the serial correlation of the panel data used in this study, the Wooldridge test is conducted. The results exhibit that $\mathrm{F}(1,35)$ $=61.436$ and the null hypothesis of no first-order autocorrelation is statistically rejected at a significance of $1 \%$. In addition to the heteroscedasticity, this study specifies the heteroskedastic and correlated errors in all estimations. Simultaneously, the approach of the feasible generalized least squares (FGLS) is employed to produce more accurate results in all estimates as well.

Table 2 presents the results of baseline estimations. In Columns (1) to (3), only control variables are incorporated. The country dummies are included in all estimations since there are substantial differences among the OECD countries. Except for that in Column (1), year dummies are added in other estimates to eliminate the estimation bias. In Columns (1) and (2), the approach of FE regression is utilized. To produce more robust and accurate estimation results, the FGLS regression is subsequently employed to conduct empirical analysis. In light of the estimation results, the exports of goods and services (Inexport) are statistically negative to carbon emissions at a significance of $1 \%$. 


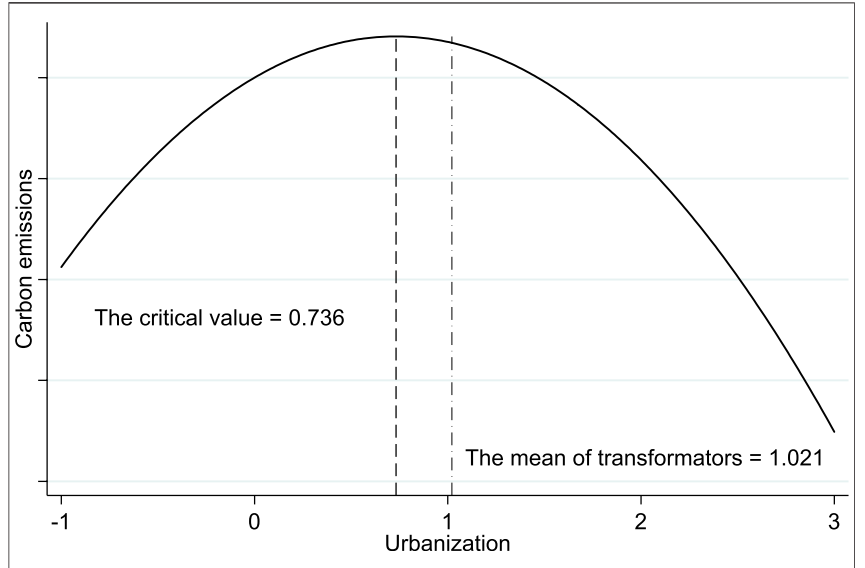

FIGURE 4 | The transformative role of government effectiveness.

The results are coherent with Khan et al. (2021), in which exports are positive to boost carbon emissions. Meanwhile, the imports of goods and services (lnimport) significantly and positively contribute to the OECD countries' carbon emissions, which is in line with the results of Khan et al. (2020). As for the economic size, the results show a significantly negative association between real GDP $(\ln r g d p)$ and carbon emissions, which is endorsed by Huang et al. (2022) and Aller et al. (2021). As assumed in the EKC hypothesis, a country with a greater economic size tends to be more environmentally friendly and thereby be more likely to improve production technologies and further positively contribute to mitigating carbon emissions. Besides, gross savings (lngrosav), the labor force (Inlabfor), and arable land (arland) are all positively associated with carbon emissions. The greater a country's gross savings, labor force, and arable land, the more products it can provide, which in turn causes the emission of more carbon. The results are aligned with Chen et al. (2019). Additionally, high-technology exports (lnhtexpt) are found to be positive to enhance carbon emissions, as verified by Aldakhil et al. (2019) and Anser et al. (2021).

In Column (4), the independent variable of urbanization is entered. In Column (5), both the variable of urbanization and its squared term are added. In terms of the results presented in Column (4), urbanization appears to be positive to increase carbon emissions. Nevertheless, the coefficient of the squared term of urbanization in Column (5) is statistically negative at a significance of $1 \%$. The results suggest that the estimation in Column (4) ignores the nonlinear effects, which also validates the adequacy of the nonlinear econometric specification. Simultaneously, the results are as hypothesized in H1. To be more specific, the critical value that transforms the effects of urbanization on carbon emissions can be calculated in light of the estimated coefficients. In Column (5), the coefficients of urbanization and its squared term are 1.694 and -0.868 , so the critical value equals 0.976 . In terms of the results of the descriptive statistics in Table 1, the mean value of urbanization is 0.761. Thus, without considering the impacts of other factors, urbanization tends to increase carbon emissions.

Figure 3 displays the nonlinear effects of urbanization on carbon emissions. The results suggest an inverted U-shaped relationship with a critical value of 0.976 . According to the definition of urbanization, it ranges from 0 to 1 . The critical level of urbanization is too high for most OECD countries to reach. Furthermore, the average level of urbanization equals 0.761 , which means that most of the OECD countries' urbanization levels are lower than the critical level. Thus, with the advancement of urbanization, the OECD countries are more likely to emit higher volumes of carbon dioxide.

\section{Robustness Check}

To produce more robust estimates, this study conducts a systematic check of robustness. Firstly, an alternative regression method of weighted least squares (WLS) is utilized. The second is to reestimate the baseline model with samples of higher and lower than average GDP per capita, respectively. Because the approach of FGLS regression is only available to balanced panel data, this study employs the method of least squares dummy variable (LSDV) to perform re-estimations. Additionally, this study also replaces the dependent variable with an alternative measure of carbon emissions, that is per capita carbon emissions.

The results of the robustness check are reported in Table 3. In Column (1), the results of WLS regression remain unchanged. In detail, the coefficients of urbanization and its squared term are statistically significant. Moreover, the critical value is equal to 0.830 , which reveals that with the improvement of urbanization, the OECD countries still emit more volume of carbon dioxide. In Columns (2) and (3), the coefficients specific to urbanization and its squared term are statistically significant as well. Especially, the critical value and mean values of urbanization for the OECD countries with a higher GDP per capita are 0.745 and 0.805 , and that for the lower GDP per capita countries are 0.621 and 0.704 . The results suggest that for higher GDP per capita countries, the enhancement of urbanization is positive to decrease carbon emissions but is the opposite in countries with a lower GDP per capita. The results are still expected as in H1. In Column (4), after replacing the measurement of the dependent variable, the coefficients of urbanization and its squared term are 1.949 and -1.083 , both of which are at a significance of $1 \%$. Furthermore, the critical value is 0.900 , and hence, the results are still aligned with that presented in Column (4) of Table 2 and Column (1) of Table 3. Thus, the results of the robustness check remain unchanged and still endorse $\mathrm{H} 1$.

\section{FURTHER DISCUSSIONS}

To address the influence channels of urbanization on carbon emissions, this study investigates the transformative role of government effectiveness. In Table 4, Column (1) again displays the baseline estimation results. Similarly, this study firstly evaluates the nonlinear associations between urbanization and government effectiveness, and the results are shown in Column (2) of Table 4. In terms of the estimation results, the coefficients of urbanization and its squared term are statistically significant, and both of them are at a significance of $1 \%$. Furthermore, the critical value is 0.649 , which is less than the mean value of urbanization. Therefore, with the enhancement of urbanization, the government effectiveness of the OECD countries will be improved. Thus, the results are aligned with $\mathrm{H} 2$. 
Secondly, this study incorporates the interactive terms of urbanization and its squared term specific to government effectiveness and performs a re-estimation. Column (3) of Table 4 presents the estimation results. Due to multicollinearity, in addition to the variable of government effectiveness, the variables of urbanization and its squared term are excluded. The coefficients of the interactive terms (tsfm 1 and $t s f m 2$ ) are 0.570 and -0.387 , and both of them are at a significance of $1 \%$. Moreover, the critical value can be calculated, which is 0.736 . Simultaneously, the mean value of transformators (rurbpop $\times g e$ ) is 1.021, which is greater than the critical value of transfomators. Under the consideration of government effectiveness, although nonlinear associations of urbanization on carbon emissions remain unchanged, the positive effects of urbanization on emitting more carbon dioxide are transformed by relatively decreasing the critical value of urbanization. Therefore, the improvement of government effectiveness negatively contributes to the effects of urbanization on increasing carbon emissions. The results imply that government effectiveness plays a transformative role, which is as expected in $\mathrm{H} 3$.

Figure 4 describes the nonlinear associations between urbanization and carbon emissions under the transformative role of government effectiveness, indicating an inverted U-shaped nexus with a critical value of 0.736 . Compared with Figure 3, the critical value of the new U-shaped curve becomes smaller, which is changed from 0.976 to 0.736 . To be more specific, transformators range from -0.169 to 2.031 , while the range of urbanization is from 0 to 1 . Furthermore, the mean values of urbanization and transformators are 0.761 and 1.021 , respectively. Therefore, it is unlikely to reduce carbon emissions by increasing urbanization. Nevertheless, government effectiveness has become a feasible and accessible path that will play a pivotal role in reducing carbon emissions in the process of urbanization.

\section{CONCLUSION AND IMPLICATIONS}

\section{Conclusion}

With the development of economic globalization, although significant economic achievements have been made, the environment is continuously degrading, and global warming has become increasingly severe. With the rapid economic growth, urbanization is also accelerating, which has increased carbon emissions and thereby has played a vital role in causing global warming. Utilizing panel data of the OECD countries from 1996 to 2018, this study evaluates the nonlinear effects of urbanization on carbon emissions. Simultaneously, the transformative role of government effectiveness in changing the affecting pattern of urbanization on carbon emissions has also been addressed in detail. To produce more accurate estimates, this study conducts regressions by utilizing the approach of the FGLS and takes the heteroskedastic and correlated errors into account. The results suggest that urbanization is nonlinearly associated with carbon emissions, indicating an inverted U-shaped curve. Compared with the critical value, the average urbanization level of the OECD countries is on the left side of the inverted U-shaped curve. Therefore, for most OECD countries, the enhancement of urbanization tends to increase carbon emissions. Besides, the results also show that urbanization positively contributes to government effectiveness, which implies that the effectiveness of the OECD countries' governments will increase as the level of urbanization rises. Furthermore, this study verifies the transformative role of government effectiveness, and the results reveal that government effectiveness negatively contributes to the effects of urbanization on increasing carbon emissions. Thus, the positive role of urbanization in emitting more carbon dioxide will be transformed to help the OECD countries mitigate carbon emissions with the advancement of government effectiveness.

\section{Policy Implications}

The empirical findings in this study provide a new understanding of the nonlinear associations between urbanization and carbon emissions as well as the transformative role of government effectiveness, which is also informative for policymakers to take effective measures to reduce carbon emissions and further mitigate global warming. Firstly, regardless of developed or developing countries are encouraged to accelerate the process of urbanization. The results of baseline estimation suggest that the mean value of most OECD countries is on the left side of the inverted U-shaped curve, and the increase in the level of urbanization will cause these countries to produce more carbon dioxide. Nevertheless, the results also indicate that urbanization is conducive to improving government effectiveness, which has been verified as a pivotal transformator in this study. Secondly, countries are recommended to formulate active measures to improve the effectiveness of government. The results exhibit that government effectiveness has played a transformative role in changing the impacts of urbanization on carbon emissions. In addition to the improvement of urbanization, the advancement of government effectiveness together helps eliminate carbon emissions, which is positive to ease global warming and prevent environmental degradation.

\section{DATA AVAILABILITY STATEMENT}

Publicly available datasets were analyzed in this study. This data can be found here: https://www.worldbank.org.

\section{AUTHOR CONTRIBUTIONS}

FC contributed to conceptualization. FC and RZ contributed to data curation and writing. AL and XL contributed to formal analysis. FC and RZ contributed to funding acquisition. JT contributed to methodology. XL and RA contributed to proofreading and editing. All authors contributed to the article and approved the submitted version.

\section{ACKNOWLEDGMENTS}

The authors acknowledge the Program for Young Excellent Talents in UIBE (Grant Nos. 18YQ07), the Key Research Project Foundation of Beijing Finance Society, and the Postgraduate Innovative Research Fund in UIBE. 


\section{REFERENCES}

Adem, M., Solomon, N., Movahhed Moghaddam, S., Ozunu, A., and Azadi, H. (2020). The Nexus of Economic Growth and Environmental Degradation in Ethiopia: Time Series Analysis. Clim. Dev. 12 (10), 943-954. doi:10.1080/ 17565529.2020.1711699

Ahmed, Z., Wang, Z., and Ali, S. (2019). Investigating the Non-linear Relationship between Urbanization and CO2 Emissions: An Empirical Analysis. Air Qual. Atmos. Health 12 (8), 945-953. doi:10.1007/s11869-019-00711-x

Aldakhil, A. M., Zaheer, A., Younas, S., Nassani, A. A., Abro, M. M. Q., and Zaman, K. (2019). Efficiently Managing Green Information and Communication Technologies, High-Technology Exports, and Research and Development Expenditures: A Case Study. J. Clean. Prod. 240, 118164. doi:10.1016/j. jclepro.2019.118164

Ali, H. S., Abdul-Rahim, A., and Ribadu, M. B. (2017). Urbanization and Carbon Dioxide Emissions in Singapore: Evidence from the ARDL Approach. Environ. Sci. Pollut. Res. 24 (2), 1967-1974. doi:10.1007/s11356-016-7935-z

Ali, S., Dogan, E., Chen, F., and Khan, Z. (2021). International Trade and Environmental Performance in Top Ten-Emitters Countries: The Role of Eco-Innovation and Renewable Energy Consumption. Sust. Dev. 29 (2), 378-387. doi:10.1002/sd.2153

Aller, C., Ductor, L., and Grechyna, D. (2021). Robust Determinants of CO2 Emissions. Energ. Econ. 96, 105154. doi:10.1016/j.eneco.2021.105154

Anser, M. K., Ahmad, M., Khan, M. A., Zaman, K., Nassani, A. A., Askar, S. E., et al. (2021). The Role of Information and Communication Technologies in Mitigating Carbon Emissions: Evidence from Panel Quantile Regression. Environ. Sci. Pollut. Res. 28 (17), 21065-21084. doi:10.1007/s11356-020-12114-y

Balsalobre-Lorente, D., Driha, O. M., Halkos, G., and Mishra, S. (2021). Influence of Growth and Urbanization on CO2 Emissions: The Moderating Effect of Foreign Direct Investment on Energy Use in BRICS. Sust. Dev. doi:10.1002/sd.2240

Chen, F., and Jiang, G. (2021). Investigating the Impact of Institutional Quality on FDI: Are There Promotional Effects in Economic Integration Regions. Sustainability 13 (20), 11309. doi:10.3390/su132011309

Chen, H., Jia, B., and Lau, S. S. Y. (2008). Sustainable Urban Form for Chinese Compact Cities: Challenges of a Rapid Urbanized Economy. Habitat Int. 32 (1), 28-40. doi:10.1016/j.habitatint.2007.06.005

Chen, M., Liu, W., and Lu, D. (2016). Challenges and the Way Forward in China's New-type Urbanization. Land Use Policy 55, 334-339. doi:10.1016/j.landusepol. 2015.07.025

Chen, Y., Li, M., Su, K., and Li, X. (2019). Spatial-Temporal Characteristics of the Driving Factors of Agricultural Carbon Emissions: Empirical Evidence from Fujian, China. Energies 12 (16), 3102. doi:10.3390/en12163102

Chen, J., Wang, L., and Li, Y. (2020). Research on the Impact of Multi-Dimensional Urbanization on China's Carbon Emissions under the Background of COP21. J. Environ. Manage. 273, 111123. doi:10.1016/j.jenvman.2020.111123

Chen, F., Jiang, G., and Kitila, G. M. (2021a). Trade Openness and CO2 Emissions: The Heterogeneous and Mediating Effects for the Belt and Road Countries. Sustainability 13 (4), 1958. doi:10.3390/su13041958

Chen, Y., Dou, S., and Xu, D. (2021b). The Effectiveness of Eco-Compensation in Environmental protection -A Hybrid of the Government and Market. J. Environ. Manage. 280, 111840. doi:10.1016/j.jenvman.2020.111840

Chen, M., Ma, M., Lin, Y., Ma, Z., and Li, K. (2022). Carbon Kuznets Curve in China's Building Operations: Retrospective and Prospective Trajectories. Sci. Total Environ. 803, 150104. doi:10.1016/j.scitotenv.2021.150104

Ciotlaus, M., Moldovan, D., Clitan, A., and Muntean, L. (2017). Choosing an Environmentally-Friendly Public Transportation System Using MultipleCriteria Analysis. Case Study: Bistrita Nasaud, Romania. Proced. Eng. 181, 396-403. doi:10.1016/j.proeng.2017.02.407

Cui, Q., and Li, Y. (2015). An Empirical Study on the Influencing Factors of Transportation Carbon Efficiency: Evidences from Fifteen Countries. Appl. Energ. 141, 209-217. doi:10.1016/j.apenergy.2014.12.040

De Koker, L., and Jentzsch, N. (2013). Financial Inclusion and Financial Integrity: Aligned Incentives? World Dev. 44, 267-280. doi:10.1016/j.worlddev.2012. 11.002

Esty, D. C., and Porter, M. E. (2005). National Environmental Performance: An Empirical Analysis of Policy Results and Determinants. Envir. Dev. Econ. 10 (4), 391-434. doi:10.1017/s1355770x05002275
Gani, A. (2012). The Relationship between Good Governance and Carbon Dioxide Emissions: Evidence from Developing Economies. J. Econ. Dev. 37 (1), 77-93. doi:10.35866/caujed.2012.37.1.004

Gera, W. (2016). Public Participation in Environmental Governance in the Philippines: The Challenge of Consolidation in Engaging the State. Land Use Policy 52, 501-510. doi:10.1016/j.landusepol.2014.02.021

Gholipour, H. F., and Farzanegan, M. R. (2018). Institutions and the Effectiveness of Expenditures on Environmental Protection: Evidence from Middle Eastern Countries. Const Polit. Econ. 29 (1), 20-39. doi:10. 1007/s10602-017-9246-x

Glaeser, E. L., and Kahn, M. E. (2004). “Chapter 56 Sprawl and Urban Growth,” in Handbook of Regional and Urban Economics (Elsevier), 2481-2527. doi:10. 1016/s1574-0080(04)80013-0

Gu, C. (2019). Urbanization: Processes and Driving Forces. Sci. China Earth Sci. 62 (9), 1351-1360. doi:10.1007/s11430-018-9359-y

Halkos, G. E., and Tzeremes, N. G. (2013). Carbon Dioxide Emissions and Governance: A Nonparametric Analysis for the G-20. Energ. Econ. 40, 110-118. doi:10.1016/j.eneco.2013.06.010

Haustein, S., and Hunecke, M. (2007). Reduced Use of Environmentally Friendly Modes of Transportation Caused by Perceived Mobility Necessities: An Extension of the Theory of Planned Behavior. J. Appl. Soc. Pyschol 37 (8), 1856-1883. doi:10.1111/j.1559-1816.2007.00241.x

Heinrich, C. J. (1999). Do Government Bureaucrats Make Effective Use of Performance Management Information? J. Public Adm. Res. Theor. 9 (3), 363-394. doi:10.1093/oxfordjournals.jpart.a024415

Huang, Y., Chen, F., Wei, H., Xiang, J., Xu, Z., and Akram, R. (2022). The Impacts of Fdi Inflows on Carbon Emissions: Economic Development and Regulatory Quality as Moderators. Front. Energ. Res. 9, 820596. doi:10.3389/fenrg.2021. 820596

Huo, T., Li, X., Cai, W., Zuo, J., Jia, F., and Wei, H. (2020). Exploring the Impact of Urbanization on Urban Building Carbon Emissions in China: Evidence from a Provincial Panel Data Model. Sust. Cities Soc. 56, 102068. doi:10.1016/j.scs. 2020.102068

Jalilian, H., Kirkpatrick, C., and Parker, D. (2007). The Impact of Regulation on Economic Growth in Developing Countries: A Cross-Country Analysis. World Dev. 35 (1), 87-103. doi:10.1016/j.worlddev.2006.09.005

Jayachandran, S. (2015). The Roots of Gender Inequality in Developing Countries. Annu. Rev. Econ. 7, 63-88. doi:10.1146/annurev-economics-080614-115404

Ji, Y., Guo, X., Zhong, S., and Wu, L. (2020). Land Financialization, Uncoordinated Development of Population Urbanization and Land Urbanization, and Economic Growth: Evidence from China. Land 9 (12), 481. doi:10.3390/ land 9120481

Jingchao, Z., and Kotani, K. (2012). The Determinants of Household Energy Demand in Rural Beijing: Can Environmentally Friendly Technologies Be Effective. Energ. Econ. 34 (2), 381-388. doi:10.1016/j.eneco.2011.12.011

Jones, D. W. (1991). How Urbanization Affects Energy-Use in Developing Countries. Energ. Policy 19 (7), 621-630. doi:10.1016/0301-4215(91)90094-5

Kaufmann, D., Kraay, A., and Mastruzzi, M. (2011). The Worldwide Governance Indicators: Methodology and Analytical Issues. Hague J. Rule L. 3 (2), 220-246. doi:10.1017/S1876404511200046

Khan, Z., Ali, S., Umar, M., Kirikkaleli, D., and Jiao, Z. (2020). Consumption-Based Carbon Emissions and International Trade in G7 Countries: The Role of Environmental Innovation and Renewable Energy. Sci. Total Environ. 730, 138945. doi:10.1016/j.scitotenv.2020.138945

Khan, Z., Murshed, M., Dong, K., and Yang, S. (2021). The Roles of Export Diversification and Composite Country Risks in Carbon Emissions Abatement: Evidence from the Signatories of the Regional Comprehensive Economic Partnership Agreement. Appl. Econ. 53 (41), 4769-4787. doi:10.1080/ 00036846.2021.1907289

Lafrance, I., and Lafrance, G. (1999). Modelling the Electricity Consumption of Cities: Effect of Urban Density. Energ. Econ. 21 (1), 53-66. doi:10.1016/S01409883(98)00007-3

Li, Y., Zhao, R., Liu, T., and Zhao, J. (2015). Does Urbanization lead to More Direct and Indirect Household Carbon Dioxide Emissions? Evidence from China during 1996-2012. J. Clean. Prod. 102, 103-114. doi:10.1016/j.jclepro.2015.04.037

Li, G., He, Q., Shao, S., and Cao, J. (2018). Environmental Non-governmental Organizations and Urban Environmental Governance: Evidence from China. J. Environ. Manage. 206, 1296-1307. doi:10.1016/j.jenvman.2017.09.076 
Li, K., Ma, M., Xiang, X., Feng, W., Ma, Z., Cai, W., et al. (2022). Carbon Reduction in Commercial Building Operations: A Provincial Retrospection in China. Appl. Energ. 306, 118098. doi:10.1016/j.apenergy.2021.118098

Liddle, B. (2011). Consumption-Driven Environmental Impact and Age Structure Change in OECD Countries. DemRes 24 (30), 749-770. doi:10.4054/DemRes. 2011.24.30

Liddle, B. (2014). Impact of Population, Age Structure, and Urbanization on Carbon Emissions/Energy Consumption: Evidence from Macro-Level, CrossCountry Analyses. Popul. Environ. 35 (3), 286-304. doi:10.1007/s11111-0130198-4

Lister, J. (2018). The Policy Role of Corporate Carbon Management: Co-regulating Ecological Effectiveness. Glob. Pol. 9 (4), 538-548. doi:10.1111/1758-5899. 12618

Ma, M., Yan, R., Du, Y., Ma, X., Cai, W., and Xu, P. (2017). A Methodology to Assess China's Building Energy Savings at the National Level: An IPAT-LMDI Model Approach. J. Clean. Prod. 143, 784-793. doi:10.1016/j.jclepro.2016. 12.046

Ma, M., Cai, W., Cai, W., and Dong, L. (2019a). Whether Carbon Intensity in the Commercial Building Sector Decouples from Economic Development in the Service Industry? Empirical Evidence from the Top Five Urban Agglomerations in China. J. Clean. Prod. 222, 193-205. doi:10.1016/j.jclepro.2019.01.314

Ma, M., Ma, X., Cai, W., and Cai, W. (2019b). Carbon-Dioxide Mitigation in the Residential Building Sector: A Household Scale-Based Assessment. Energ. Convers. Manag. 198, 111915. doi:10.1016/j.enconman.2019.111915

Marcotullio, P. J., Sarzynski, A., Albrecht, J., and Schulz, N. (2012). The Geography of Urban Greenhouse Gas Emissions in Asia: A Regional Analysis. Glob. Environ. Change 22 (4), 944-958. doi:10.1016/j.gloenvcha.2012.07.002

Martínez-Zarzoso, I., and Maruotti, A. (2011). The Impact of Urbanization on CO2 Emissions: Evidence from Developing Countries. Ecol. Econ. 70 (7), 1344-1353. doi:10.1016/j.ecolecon.2011.02.009

Mi, Z., Meng, J., Guan, D., Shan, Y., Song, M., Wei, Y.-M., et al. (2017). Chinese CO2 Emission Flows Have Reversed since the Global Financial Crisis. Nat. Commun. 8 (1), 1712. doi:10.1038/s41467-017-01820-w

Muñoz, P., Zwick, S., and Mirzabaev, A. (2020). The Impact of Urbanization on Austria's Carbon Footprint. J. Clean. Prod. 263, 121326. doi:10.1016/j.jclepro. 2020.121326

O’Neill, B. C., Liddle, B., Jiang, L., Smith, K. R., Pachauri, S., Dalton, M., et al. (2012). Demographic Change and Carbon Dioxide Emissions. Lancet 380 (9837), 157-164. doi:10.1016/S0140-6736(12)60958-1

Okada, A. (2012). Is an Increased Elderly Population Related to Decreased CO2 Emissions from Road Transportation. Energ. Policy 45 (Jun), 286-292. doi:10. 1016/j.enpol.2012.02.033

Pu, Y., Wang, Y., and Wang, P. (2020). Driving Effects of Urbanization on CityLevel Carbon Dioxide Emissions: From Multiple Perspectives of Urbanization. Int. J. Urban Sci., 1-21. doi:10.1080/12265934.2020.1803105

Ronaghi, M., Reed, M., and Saghaian, S. (2020). The Impact of Economic Factors and Governance on Greenhouse Gas Emission. Environ. Econ. Pol. Stud. 22 (2), 153-172. doi:10.1007/s10018-019-00250-w

Sadorsky, P. (2014). The Effect of Urbanization on CO2 Emissions in Emerging Economies. Energ. Econ. 41, 147-153. doi:10.1016/j.eneco.2013.11.007

Sbia, R., Shahbaz, M., and Hamdi, H. (2014). A Contribution of Foreign Direct Investment, Clean Energy, Trade Openness, Carbon Emissions and Economic Growth to Energy Demand in Uae. Econ. Model. 36, 191-197. doi:10.1016/j. econmod.2013.09.047

Sereenonchai, S., Xu, P., Arunrat, N., and Yu, X. (2017). Diffusion and Adoption Behavior of Environmentally Friendly Innovation: Sharing from Chinese Society. J. Behav. Sci. 12 (2), 90-109. Available from: https://so06.tci-thaijo. org/index.php/IJBS/article/view/78325.

Shao, W. (2016). Weather, Climate, Politics, or God? Determinants of American Public Opinions toward Global Warming. Environ. Polit. 26 (1), 71-96. doi:10. 1080/09644016.2016.1223190

Sheng, P., and Guo, X. (2016). The Long-Run and Short-Run Impacts of Urbanization on Carbon Dioxide Emissions. Econ. Model. 53, 208-215. doi:10.1016/j.econmod.2015.12.006

Sun, W., and Huang, C. (2020). How Does Urbanization Affect Carbon Emission Efficiency? Evidence from China. J. Clean. Prod. 272, 122828. doi:10.1016/j. jclepro.2020.122828
Wang, Y., Han, R., Li, L., Kubota, J., Zhu, X., and Lu, G. (2016). Does Urbanization Lead to More Carbon Emission? Evidence from a Panel of BRICS Countries. Appl. Energ. 168, 375-380. doi:10.1016/j.apenergy.2016.01.105

Wang, Y., Ma, X., Duan, F., and He, L. (2019). Carbon Emissions Efficiency in China: Key Facts from Regional and Industrial Sector. J. Clean. Prod. 206, 850-869. doi:10.1016/j.jclepro.2018.09.185

Wang, W.-Z., Liu, L.-C., Liao, H., and Wei, Y.-M. (2021). Impacts of Urbanization on Carbon Emissions: An Empirical Analysis from OECD Countries. Energy Policy 151, 112171. doi:10.1016/j.enpol.2021.112171

Wu, Q. (2007). The Making of a Market Economy in China: Transformation of Government Regulation of Market Development. Eur. L. J. 13 (6), 750-771. doi:10.1111/j.1468-0386.2007.00394.x

Xu, Q., Dong, Y.-X., and Yang, R. (2018). Urbanization Impact on Carbon Emissions in the Pearl River Delta Region: Kuznets Curve Relationships. J. Clean. Prod. 180, 514-523. doi:10.1016/j.jclepro.2018.01.194

Yang, J., Cai, W., Ma, M., Li, L., Liu, C., Ma, X., et al. (2020). Driving Forces of China's CO2 Emissions from Energy Consumption Based on Kaya-LMDI Methods. Sci. Total Environ. 711, 134569. doi:10.1016/j.scitotenv.2019.134569

Yao, X., Kou, D., Shao, S., Li, X., Wang, W., and Zhang, C. (2018). Can Urbanization Process and Carbon Emission Abatement Be Harmonious? New Evidence from China. Environ. Impact Assess. Rev. 71, 70-83. doi:10. 1016/j.eiar.2018.04.005

Zeng, L., Lu, H., Liu, Y., Zhou, Y., and Hu, H. (2019). Analysis of Regional Differences and Influencing Factors on China's Carbon Emission Efficiency in 2005-2015. Energies 12 (16), 3081. doi:10.3390/en12163081

Zhang, X., Geng, Y., Shao, S., Wilson, J., Song, X., and You, W. (2020). China's Non-fossil Energy Development and its 2030 CO2 Reduction Targets: The Role of Urbanization. Appl. Energ. 261, 114353. doi:10.1016/j.apenergy.2019. 114353

Zhang, D., Wang, Z., Li, S., and Zhang, H. (2021). Impact of Land Urbanization on Carbon Emissions in Urban Agglomerations of the Middle Reaches of the Yangtze River. Int. J. Environ. Res. Public Health 18 (4), 1403. doi:10.3390/ ijerph18041403

Zhang, S., Ma, M., Li, K., Ma, Z., Feng, W., and Cai, W. (2022). Historical Carbon Abatement in the Commercial Building Operation: China versus the Us. Energ. Econ. 105, 105712. doi:10.1016/j.eneco.2021.105712

Zhang, W., and Xu, H. (2017). Effects of Land Urbanization and Land Finance on Carbon Emissions: A Panel Data Analysis for Chinese Provinces. Land Use Policy 63, 493-500. doi:10.1016/j.landusepol.2017.02.006

Zhang, Y.-J. (2011). The Impact of Financial Development on Carbon Emissions: An Empirical Analysis in China. Energ. Policy 39 (4), 2197-2203. doi:10.1016/j. enpol.2011.02.026

Zhou, X., Zhang, J., and Li, J. (2013). Industrial Structural Transformation and Carbon Dioxide Emissions in China. Energ. Policy 57, 43-51. doi:10.1016/j. enpol.2012.07.017

Zhou, C., Wang, S., and Wang, J. (2019). Examining the Influences of Urbanization on Carbon Dioxide Emissions in the Yangtze River Delta, China: Kuznets Curve Relationship. Sci. Total Environ. 675, 472-482. doi:10.1016/j.scitotenv.2019. 04.269

Conflict of Interest: The authors declare that the research was conducted in the absence of any commercial or financial relationships that could be construed as a potential conflict of interest.

Publisher's Note: All claims expressed in this article are solely those of the authors and do not necessarily represent those of their affiliated organizations, or those of the publisher, the editors and the reviewers. Any product that may be evaluated in this article, or claim that may be made by its manufacturer, is not guaranteed or endorsed by the publisher.

Copyright (c) 2022 Chen, Liu, Lu, Zhe, Tong and Akram. This is an open-access article distributed under the terms of the Creative Commons Attribution License (CC $B Y)$. The use, distribution or reproduction in other forums is permitted, provided the original author(s) and the copyright owner(s) are credited and that the original publication in this journal is cited, in accordance with accepted academic practice. No use, distribution or reproduction is permitted which does not comply with these terms. 